\title{
Nephrometry score-guided off-clamp laparoscopic partial nephrectomy: patient selection and short-time functional results
}

Hong-Kai Wang ${ }^{1,2}$, Xiao-Jian Qin ${ }^{1,2}$, Chun-Guang Ma ${ }^{1,2}$, Guo-Hai Shi ${ }^{1,2}$, Hai-Liang Zhang ${ }^{1,2^{*}}$ and Ding-Wei Ye ${ }^{1,2^{*}}$

\begin{abstract}
Background: Laparoscopic partial nephrectomy (LPN) is not a novel but a relatively technically challenging surgical procedure. Off-clamp LPN with zero ischemia can completely eliminate ischemic reperfusion injury to the kidney.

The purpose of this study was to evaluate the safety and functional outcome of nephrometry score-guided off-clamp technique in LPN.

Methods: A total of 44 patients underwent LPN between January 2015 and July 2015 for renal mass with radius, exophytic/endophytic, nearness to sinus, anterior/posterior location (RENAL) score 4 were enrolled. Twenty-two of them underwent off-clamp LPN with zero ischemia, and the other 22 received standard LPN with common renal artery clamp. Estimate blood loss (EBL), total operation time, resection time, renorrhaphy time, preoperative estimated glomerular filtration rate (eGFR), postoperative eGFR, eGFR change, and drainage after surgery were compared between these two groups using $t$ test.
\end{abstract}

Results: Patients' characteristics including gender, age, BMI, tumor size, and RENAL score were balanced between the two groups. Average EBL was more in the off-clamp group than in the on-clamp group (134.32 versus $70.23 \mathrm{ml}$, $p=0.001)$. Average eGFR change was less in the off-clamp group than in the on-clamp group $(-1.56$ versus -6.45 , $p<0.001$ ). Average drainage after surgery was $203.41 \mathrm{ml}$ for the off-clamp group and $145.46 \mathrm{ml}$ for the on-clamp group, $p=0.062$. No urinary leakage and hematuria occurred in both groups. There were no statistical difference in total operation time, resection time, renorrhaphy time, preoperative eGFR, and postoperative eGFR between the two groups.

Conclusions: Off-clamp LPN is a safe and feasible approach to excise certain kidney tumors with RENAL score 4. This technique can better preserve kidney function without ischemic reperfusion injury.

Keywords: Renal cell carcinoma, Laparoscopic partial nephrectomy, Zero ischemia, Nephrometry score

Abbreviations: LPN, Laparoscopic partial nephrectomy; EBL, Estimate blood loss; eGFR, Estimated glomerular filtration rate; BMI, Body mass index; RCC, Renal cell carcinoma; RN, Radical nephrectomy; PN, Partial nephrectomy; NCCN, National Comprehensive Cancer Network; AJCC, American Joint Committee on Cancer; CT, Computed tomography; MRI, Magnetic resonance image

\footnotetext{
*Correspondence: zhangh1918@163.com; dwyeli@163.com

Hong-Kai Wang and Xiao-Jian Qin are co-first authors.

'Department of Urology, Fudan University Shanghai Cancer Center, 270

Dong'an Rd (M), Shanghai 200032, China

Full list of author information is available at the end of the article
} 


\section{Background}

The incidence of renal cell carcinoma (RCC) has been increasing over the past decades $[1,2]$. Radical nephrectomy (RN) remains the standard care for localized tumors, while this surgery procedure largely decreases kidney function and sequentially exposes the patient to greater cardiovascular morbidity and mortality risks in their future time [3]. According to the 2015 NCCN guideline, partial nephrectomy $(\mathrm{PN})$ is recommended to preserve kidney function for patients with an AJCC stage T1a tumor. However, ischemic reperfusion injury is inevitable if renal artery is temporary clamped during the surgical procedure [4]. A recent study indicated that every minute of ischemia imparted additional risk for postoperative renal dysfunction [5]. Cold ischemia method may theoretically provide better protection to kidney function, while the benefit is minimal because it usually prolongs the ischemic time for cooling the kidney [6].

The term "zero ischemia" implies that both tumor resection and renorrhaphy were completed without hilar clamping and ischemic stress [7]. Selective/segmental renal artery clamping is used to preserve the remnant kidney tissue besides the tumor $[8,9]$. Nevertheless, it is not real zero ischemia for the whole kidney, and only skillful oncological urologist can perform this challenging work [10]. Laser-supported [11], radio frequency (RF)assisted [12], hydro-jet-assisted [13-15], and microwaveassisted [16] off-clamping PN can achieve true zero ischemic surgery. However, positive surgical margin or complications such as calyceal injury, urinary leakage, and venous injuries are difficult to completely eliminate in these ablation assisted PN $[17,18]$.

Anatomy-based nephrometry scoring systems such as radius, exophytic/endophytic, nearness to sinus, anterior/ posterior location (RENAL) score [19], preoperative aspects and dimensions used for anatomic (PADUA) classification [20], centrality index [21], and contact surface area [22] have been assigned to guide clinical decisions on nephron-sparing surgery or radical nephrectomy.

We here adopted a novel RENAL score-guided offclamp laparoscopic partial nephrectomy (LPN) technique in selected patients, to completely avoid renal ischemic injury and prevent some of the incidents related to renal hilar dissection and clamping during LPN. In this paper, we present our experience with off-clamp LPN and demonstrate the patient selection criteria and the outcome of this technique compared with standard on-clamp LPN.

\section{Methods}

\section{Patients}

After institutional review board approval, we enrolled 44 consecutive patients who underwent retroperitoneal LPN at our institute, between January 2015 and July
2015. The including criteria on kidney tumors were exophytic, solid or cystic, RENAL score 4 [19]; maximum diameter $\leq 3 \mathrm{~cm}$; and suspicious for malignancy on computed tomography (CT) scan or magnetic resonance image (MRI). All the LPNs were performed sequentially one by one for off-clamp LPN with zero ischemia or standard LPN with common renal artery clamp by the same surgeon (Ye DW). Twenty-two patients underwent off-clamp LPN, and the other 22 received standard LPN. Patients' demographics; main operative and outcome variables including estimate blood loss (EBL), total operation time, resection time, renorrhaphy time, preoperative estimated glomerular filtration rate (eGFR), 24-48-h postoperative eGFR, eGFR change, drainage after surgery, and length of hospital stay; and tumors' histopathological results (size, site, side, and grade) were prospectively collected according to Fuhrman grading system and the 2004 WHO classification [23].

\section{Major surgical procedures}

The patients were administered general anesthesia and placed in the lateral decubitus position. Three ports in the lumbar region were applied. After establishing the retroperitoneal cavity, the kidney was mobilized as necessary to expose the tumor completely (Fig. 1a). Intraoperative ultrasound was used to measure the diameter and depth of the tumor. Before resection of the tumor, the common renal artery was dissected and clamped only in the 22 patients under on-clamp LPN. Scissors were used to open the renal capsule $2 \sim 3 \mathrm{~mm}$ away from the tumor and further cutting deep into the renal cortex slowly and carefully around the tumor (Fig. 1b, c). Bipolar coagulation was applied when small arterial bleeding occurred. After complete excision of the tumor, the margin of resection was sent to pathology for the frozen section to ensure complete excision of the tumor. Then, the parenchymal defect was closed using Hem-o-lok clips to tighten and secure the sutures at each exit point (Fig. 1d). Pneumoperitoneum pressure was temporarily risen to $18 \mathrm{mmHg}$ during tumor resection and renorrhaphy. No hemostatic agents were used during the procedure.

\section{Follow-up}

Preoperative serum creatinines were performed within 1 week before surgery, and postoperative measurements were tested within 1 week after surgery. Estimated GFR (eGFR) (units $=\mathrm{ml} / \mathrm{min} / 1.73 \mathrm{~m}^{2}$ ) was calculated by the modification of diet in renal disease equation [24].

\section{Statistical analyses}

All statistical analyses were performed using SPSS version 19.0 statistical software (SPSS Inc., Chicago, IL) after conducting the univariate analyses for the variable, the relationship between the main studied variables, 


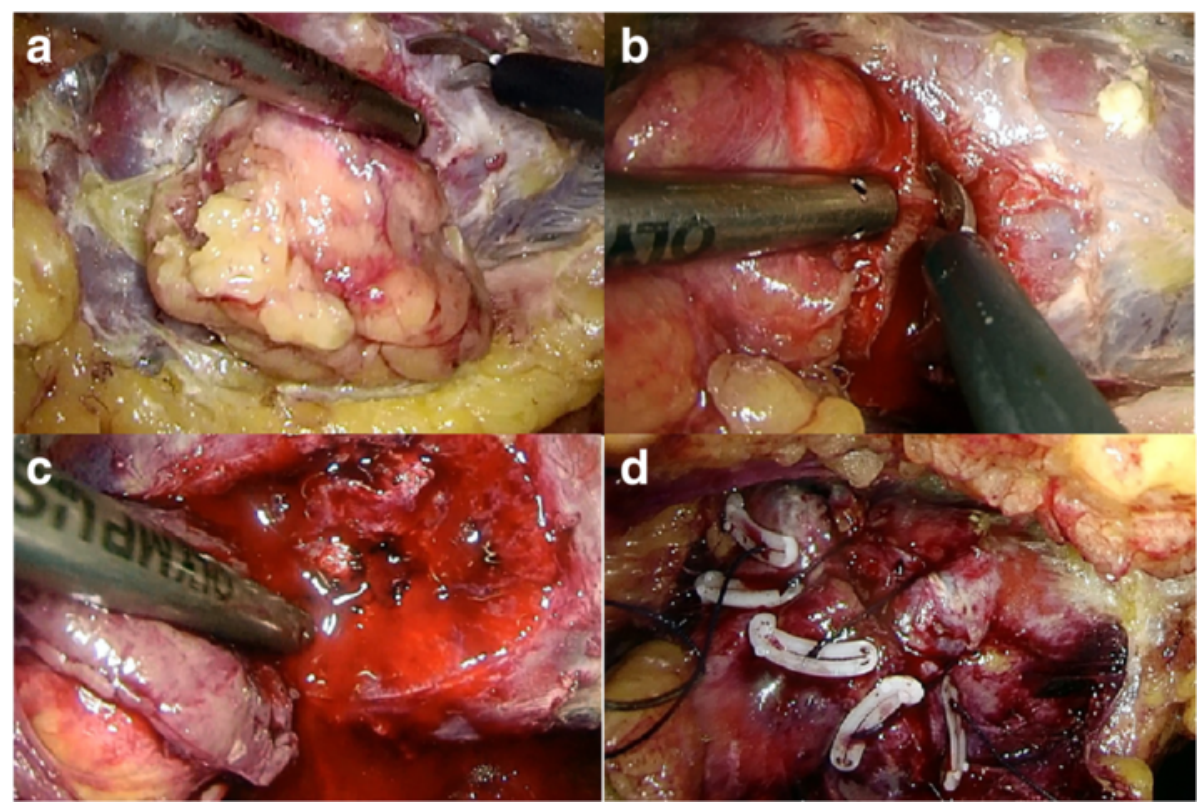

Fig. 1 Surgical procedure for off-clamp laparoscopic partial nephrectomy. a Mobilization of the kidney and complete exposure of the tumor. b, c Tumor resection using cold scissors. d Renorrhaphy using Hem-o-lok clips to tighten and secure the sutures at each exit point

serum creatinine values, EBL, length of hospital stay, main surgical complications, patients' age and gender, and subtype, size, and grade of tumors. Categorical data were analyzed using chi-square. Pearson correlation coefficients were calculated between continuous variables. $p$ values of 0.05 or less were considered statistically significant.

\section{Results}

\section{Preoperative patient and tumor demographics}

A total of 44 patients (22 off-clamp LPN, 22 on-clamp LPN) participated in the study (Table 1). The mean age was 54.36 years for the off-clamp group and 54.41 years for the on-clamp group. Male to female ratios were both 16:6 for the two groups. BMI was equal between groups, mean 25.43 versus $24.10 \mathrm{~kg} / \mathrm{m}^{2}$. Mean tumor size and intra-kidney tumor size (maximum tumor diameter within renal parenchyma) were 19.86 and $18.46 \mathrm{~mm}$ for the off-clamp group and 19.14 and $17.68 \mathrm{~mm}$ for the on-clamp group, respectively, also having no statistical difference. There was also no statistical difference between two groups in tumor side and position.

\section{Surgical outcome}

All patients had negative surgical margins without complications of postoperative hematuria, delayed bleeding, and urinary leakage. There was no need to convert any of the cases to clamped technique or to the open technique. Average EBL was $134.32 \pm 70.11$ and $70.23 \pm$ $39.75 \mathrm{ml}$ in the off-clamp group and the on-clamp group, respectively, $p<0.001$. Tumor resection time was longer for the off-clamp patients than for the on-clamp patients (5.86 \pm 2.17 versus $4.55 \pm 1.47 \mathrm{~min}, p=0.023)$. No statistical difference was detected between the two groups on total operation time, renorrhaphy time, postoperative drainage, postoperative bed time, and main surgical complications (Table 2).

Table 1 Patients' preoperative demographics

\begin{tabular}{|c|c|c|c|}
\hline \multirow[t]{2}{*}{ Factors } & Off-clamp & On-clamp & \multirow[t]{2}{*}{$p$ value } \\
\hline & (22 cases) & (22 cases) & \\
\hline \multicolumn{4}{|l|}{ Gender } \\
\hline Male & 16 & 16 & 1.000 \\
\hline Female & 6 & 6 & \\
\hline Age (years, mean $\pm S D$ ) & $54.36 \pm 12.07$ & $54.41 \pm 10.40$ & 0.989 \\
\hline Height (cm, mean \pm SD) & $166.68 \pm 6.59$ & $166.09 \pm 7.49$ & 0.782 \\
\hline Weight (kg, mean $\pm \mathrm{SD})$ & $71.00 \pm 11.77$ & $66.52 \pm 9.01$ & 0.164 \\
\hline $\mathrm{BMI}\left(\mathrm{kg} / \mathrm{cm}^{2}\right.$, mean $\left.\pm \mathrm{SD}\right)$ & $25.43 \pm 2.83$ & $24.10 \pm 2.76$ & 0.122 \\
\hline Tumor size $(\mathrm{mm}$, mean $\pm \mathrm{SD})$ & $19.86 \pm 5.48$ & $19.14 \pm 5.97$ & 0.676 \\
\hline $\begin{array}{l}\text { Tumor size intra-kidney } \\
(\mathrm{mm} \text {, mean } \pm \mathrm{SD})\end{array}$ & $18.46 \pm 4.13$ & $17.68 \pm 4.69$ & 0.565 \\
\hline \multicolumn{4}{|l|}{ Side of the kidney } \\
\hline Left & 12 & 7 & 0.128 \\
\hline Right & 10 & 15 & \\
\hline \multicolumn{4}{|l|}{ Position of tumor } \\
\hline Upper pole & 5 & 4 & 0.831 \\
\hline Middle & 10 & 12 & \\
\hline Lower pole & 7 & 6 & \\
\hline
\end{tabular}


Table 2 Postoperative characteristics

\begin{tabular}{|c|c|c|c|}
\hline \multirow[t]{2}{*}{ Factors } & Off-clamp & On-clamp & \multirow[t]{2}{*}{$p$ value } \\
\hline & (22 cases) & (22 cases) & \\
\hline \multicolumn{4}{|l|}{ Subtypes } \\
\hline Clear cell & 16 & 16 & 0.446 \\
\hline Papillary & 4 & 2 & \\
\hline Chromophobe & 2 & 2 & \\
\hline Oncocytoma & 0 & 2 & \\
\hline \multicolumn{4}{|l|}{ Grade } \\
\hline 1 & 2 & 2 & \multirow[t]{4}{*}{0.462} \\
\hline 2 & 14 & 9 & \\
\hline 3 & 4 & 7 & \\
\hline Not applicable & 2 & 4 & \\
\hline $\begin{array}{l}\text { Resection time } \\
(\text { min, mean } \pm S D)\end{array}$ & $5.86 \pm 2.17$ & $4.55 \pm 1.47$ & 0.023 \\
\hline $\begin{array}{l}\text { Renorrhaphy time } \\
\text { (min, mean } \pm S D)\end{array}$ & $16.00 \pm 3.75$ & $14.73 \pm 2.25$ & 0.18 \\
\hline $\begin{array}{l}\text { Estimated blood loss } \\
(\mathrm{ml}, \text { mean } \pm \mathrm{SD})\end{array}$ & $134.32 \pm 70.11$ & $70.23 \pm 39.75$ & 0.001 \\
\hline Drainage $(m l$, mean $\pm S D)$ & $203.41 \pm 124.17$ & $145.46 \pm 68.29$ & 0.062 \\
\hline $\begin{array}{l}\text { Operation time } \\
(\text { min, mean } \pm S D)\end{array}$ & $75.00 \pm 16.97$ & $82.27 \pm 16.10$ & 0.152 \\
\hline $\begin{array}{l}\text { Postoperative bed time } \\
\text { (day, mean } \pm \text { SD) }\end{array}$ & $5.77 \pm 1.19$ & $5.68 \pm 1.13$ & 0.796 \\
\hline $\begin{array}{l}\text { eGFR preoperation } \\
\left(\mathrm{ml} / \mathrm{min} / 1.73 \mathrm{~m}^{2}, \text { mean } \pm \mathrm{SD}\right)\end{array}$ & $86.43 \pm 19.92$ & $90.66 \pm 21.13$ & 0.594 \\
\hline $\begin{array}{l}\text { eGFR postoperation } \\
\left(\mathrm{ml} / \mathrm{min} / 1.73 \mathrm{~m}^{2} \text {, mean } \pm \mathrm{SD}\right)\end{array}$ & $84.87 \pm 21.72$ & $84.21 \pm 28.77$ & 0.932 \\
\hline $\begin{array}{l}\text { eGFR change } \\
\left(\mathrm{ml} / \mathrm{min} / 1.73 \mathrm{~m}^{2}, \text { mean } \pm \mathrm{SD}\right)\end{array}$ & $-1.56 \pm 4.70$ & $-6.45 \pm 3.83$ & $<0.001$ \\
\hline Hematuria & 0 & 0 & 1.000 \\
\hline Postoperative hemorrhage & 0 & 0 & 1.000 \\
\hline Blood transfusion & 0 & 0 & 1.000 \\
\hline Urinary leakage & 0 & 0 & 1.000 \\
\hline \multicolumn{4}{|l|}{$\begin{array}{l}\text { Clavien-Dindo classification } \\
\text { of surgical complications }\end{array}$} \\
\hline Grades 1-2 & 22 & 22 & 1.000 \\
\hline Grades 3-5 & 0 & 0 & \\
\hline
\end{tabular}

\section{Pathological outcomes}

Histopathological subtypes were clear-cell RCC $(n=32$, 16 in the off-clamp group and 16 in the on-clamp group), papillary $\mathrm{RCC}(n=6,4$ in the off-clamp group and 2 in the on-clamp group), chromophobe RCC ( $n=$ 4,2 in the off-clamp group and 2 in the on-clamp group), and oncocytoma $(n=2,2$ in the on-clamp group). Fuhrman grades were grade $1(n=4,2$ in the off-clamp group and 2 in the on-clamp group), grade 2 ( $n=23,14$ in the off-clamp group and 9 in the on-clamp group), grade 3 ( $n=11,4$ in the off-clamp group and 7 in the on-clamp group), and not applicable ( $n=6,2$ in the off-clamp group and 4 in the on-clamp group).

\section{Renal functional evaluation}

Mean preoperative serum eGFRs were $86.43 \pm 19.92 \mathrm{ml} /$ min in the off-clamp group and $90.66 \pm 21.13 \mathrm{ml} / \mathrm{min}$ in the on-clamp group, $p=0.594$. Mean postoperative serum eGFRs were $84.87 \pm 21.72 \mathrm{ml} / \mathrm{min}$ in the off-clamp group and $84.21 \pm 28.77 \mathrm{ml} / \mathrm{min}$ in the on-clamp group, $p=0.932$. Mean eGFR changes were $-1.56 \pm 4.70 \mathrm{ml} / \mathrm{min}$ in the off-clamp group and $-6.45 \pm 3.83 \mathrm{ml} / \mathrm{min}$ in the on-clamp group, $p<0.001$.

\section{Discussion}

Minimally invasive nephron-sparing surgery has become a favorable option by many surgeons and many patients as it is showing outstanding oncologic outcome and at the same time maintaining good renal function [25, 26]. How to better preserve the renal function has always been a key problem in the treatment of kidney tumors. A few auxiliary means, such as cold ischemia, selective renal artery clamping, segmental renal artery clamping, renal parenchymal clamping, superselective embolization, radio frequency, laser, microwave, and hydro-jet, have achieved some benefits, while these methods have their own disadvantages and deficiencies [27]. We here proposed the RENAL score guidance for the retroperitoneal laparoscopic zero ischemia nephron-sparing surgery and performed tentative attempts to obtain preliminary outcomes.

The existing nephrometry scoring systems can assist in clinical decision-making on radical nephrectomy (RN) versus $\mathrm{PN}$ or open versus minimally invasive $\mathrm{PN}$. They can also inform the surgeon regarding technical difficulty during minimally invasive $\mathrm{PN}$ for a given mass and have been correlated with ischemia time, operation time, blood loss, complications, and the likelihood of conversion from PN to RN [28]. However, they lack evidence in guiding off-clamp zero ischemia minimally invasive PN. We first introduced RENAL score to guide the zero ischemia LPN, and the results show that this surgical technique was safe and feasible in RENAL score 4 renal mass.

The RENAL nephrometry score consists of five anatomic radiologic properties: (R)adius/maximal tumor diameter, (E)xophytic/endophytic properties, (N)earness to the collecting system or sinus, (A)nterior(a)/posterior(p)/ not anterior or posterior (x) descriptor, and (L)ocation relative to the polar line. For each variable except A, 1 to 3 points are assigned, which yield a total of 4 points for the least complex and 12 points for the most complex mass. Masses are classified as low complexity (RENAL scores 4-6), moderate complexity (scores 7-9), or high complexity (scores 10-12) [19]. Herein, we choose tumors of RENAL score 4 and maximum diameter less 
than $3 \mathrm{~cm}$ as candidates for off-clamp retroperitoneal LPN, because these tumors are the least complex with least surgical complications including bleeding, renal pelvis injury, urinary leakage, and hematuria [29]. Thompson et al. also proposed that off-clamp PN can reduce the hazard of both acute and chronic kidney disease. Our outcomes demonstrated that off-clamp operation was safe in these well-selected cases, with only a bit more bleeding but better protection of kidney function than that of the on-clamp group.

EBL was more in the off-clamp patients than in the on-clamp cases. This was reasonable for zero ischemia surgery. We temporarily raise pneumoperitoneum pressure to $18 \mathrm{mmHg}$ when removing the tumor and suturing the wound of the kidney. We hope this procedure can decrease blood loss during off-clamp LPN. Rizkala and colleagues had described their novel zero ischemia robotic PN technique in 2013, that is, sequential preplaced suture renorrhaphy technique [30]. Compared to straightforward excision without hilar clamping, preplacing sutures sequentially aids in providing better visualization secondary to a decrease in bleeding onto the tumor bed. However, this procedure is completed under robotic surgery, and we may attempt to add this technique to our zero ischemia LPN in the future.

Postoperative drainage also seemed to be more in the off-clamp group, although there was no statistical significance. We used cold scissors and suction to remove the tumor because this could provide better incision plane to ensure complete resection and not cut into the tumor in such a continuous bleeding situation. Energy-cutting equipment such as Valley ForceTriad energy platform, high-frequency electrosurgical equipment, and a HARMONIC ACE+ shears ultrasonic knife were not considered suitable for tumor resection in an off-clamp zero ischemic situation with continuous bleeding. Coagulation was poor with a lot of eschar which made the plane blurred and indistinct for perfect resection. ERBE VIO + BiSect/BiCamp bipolar coagulation was effective in handling small artery hemorrhage but difficult in controlling a large area of venous bleeding from the tumor bed. For venous bleeding, suturing remains the most reliable method.

The kidney tissue was more brittle in off-clamp condition and easy to be torn during suturing if the suture was pulled too hard [28]. We preferred to use Polysorbbraided absorbable suture 1 (COVIDIEN Inc.) in renorrhaphy, because it was thicker enough to reduce cutting into normal kidney tissue and firm enough to pull the apart kidney incision together. Barbed sutures are not recommended because they are too rough and bleeding is more prone to occur in the needle site.

A limitation of our technique is its limited use for high RENAL score tumors. For those tumors, robotic surgery may be helpful in better tumor resection and renorrhaphy. Another limitation for the current study is its small sample size with only short-term results. External validation of these data with larger cohorts and long-term follow-up especially eGFR change over 12 months are required.

\section{Conclusions}

We compared off-clamping and main artery clamping in LPN. The off-clamping cohort was associated with a longer tumor resection time and more EBL. Functional outcome of eGFR changes seemed superior in the offclamping cohort. As we continue to implement this technique, we hope to further assess its long-term safety and oncological effectiveness.

\section{Acknowledgements}

Not applicable.

Funding

This work is supported by the National Natural Science Foundation of China (NSFC) 81202004

\section{Availability of data and materials}

All datasets supporting the conclusions of this article are included within the current article.

\section{Authors' contributions}

$\mathrm{HW}$ and $\mathrm{XQ}$ acquired the data, enrolled the patients, and drafted the manuscript. CM and GS analyzed and interpreted the data, prepared all the figures, and edited all the tables. DY and $\mathrm{HZ}$ designed and supervised the study. All authors reviewed and approved the manuscript.

\section{Competing interests}

The authors declare that they have no competing interests.

\section{Consent for publication}

Not applicable.

Ethics approval and consent to participate

The present study was carried out in accordance with the ethical standards of Helsinki Declaration II and approved by the Institution Review Board of Fudan University Shanghai Cancer Center. Written informed consent was obtained from each patient before any study-specified investigation was performed.

\section{Author details}

${ }^{1}$ Department of Urology, Fudan University Shanghai Cancer Center, 270 Dong'an Rd (M), Shanghai 200032, China. '2Department of Oncology,

Shanghai Medical College, Fudan University, Shanghai, People's Republic of China.

Received: 27 February 2016 Accepted: 14 June 2016

Published online: 21 June 2016

\section{References}

1. Ljungberg B, Campbell SC, Choi HY, et al. The epidemiology of renal cell carcinoma. Eur Urol. 2011;60(4):615-21.

2. Cho E, Adami HO, Lindblad P. Epidemiology of renal cell cancer. Hematol Oncol Clin North Am. 2011;25(4):651-65.

3. Go AS, Chertow GM, Fan D, et al. Chronic kidney disease and the risks of death, cardiovascular events, and hospitalization. N Engl J Med. 2004; 351(13):1296-305

4. Choi JD, Park JW, Lee SY, et al. Does prolonged warm ischemia after partial nephrectomy under pneumoperitoneum cause irreversible damage to the affected kidney? J Urol. 2012;187(3):802-6. 
5. Patel AR, Eggener SE. Warm ischemia less than 30 minutes is not necessarily safe during partial nephrectomy: every minute matters. Urol Oncol. 2011; 29(6):826-8.

6. Volpe A, Blute ML, Ficarra V, et al. Renal ischemia and function after partial nephrectomy: a collaborative review of the literature. Eur Urol. 2015;68(1):61-74.

7. Gill IS, Eisenberg MS, Aron M, et al. "Zero ischemia" partial nephrectomy: novel laparoscopic and robotic technique. Eur Urol. 2011;59(1):128-34.

8. Shao $P$, Tang $L, L i P$, et al. Precise segmental renal artery clamping under the guidance of dual-source computed tomography angiography during laparoscopic partial nephrectomy. Eur Urol. 2012;62(6):1001-8.

9. Shao P, Qin C, Yin C, et al. Laparoscopic partial nephrectomy with segmental renal artery clamping: technique and clinical outcomes. Eur Urol. 2011;59(5):849-55.

10. $\mathrm{Ng} \mathrm{CK}$, Gill IS, Patil MB, et al. Anatomic renal artery branch microdissection to facilitate zero-ischemia partial nephrectomy. Eur Urol. 2012;61(1):67-74.

11. Bui MH, Breda A, Gui D, et al. Less smoke and minimal tissue carbonization using a thulium laser for laparoscopic partial nephrectomy without hilar clamping in a porcine model. J Endourol. 2007;21(9):1107-11.

12. Patel HD, Pierorazio PM, Mullins JK, et al. Radiofrequency coagulationassisted laparoscopic partial nephrectomy without hilar clamping: a feasible technique with excellent outcomes in highly selected patients. J Endourol. 2012:26(1):58-62.

13. Moinzadeh A1, Hasan W, Spaliviero M, et al. Water jet assisted laparoscopic partial nephrectomy without hilar clamping in the calf model. J Urol. 2005; 174(1):317-21.

14. Gao Y, Chen L, Ning Y, et al. Hydro-jet-assisted laparoscopic partia nephrectomy with no renal arterial clamping: a preliminary study in a single center. Int Urol Nephrol. 2014;46(7):1289-93.

15. Simone G, Papalia R, Guaglianone S, et al. Zero ischaemia, sutureless laparoscopic partial nephrectomy for renal tumors with a low nephrometry score. BJU Int. 2012;110(1):124-30

16. Kawai N, Yasui T, Umemoto Y, et al. Laparoendoscopic single-site partial nephrectomy without hilar clamping using a microwave tissue coagulator. J Endourol. 2014;28(2):184-90.

17. Janetschek G. Laparoscopic partial nephrectomy for RCC: how can we avoid ischemic damage of the renal parenchyma? Eur Urol. 2007;52(5):1303-5.

18. Castro Jr A, Jenkins LC, Salas N, et al. Ablative therapies for small renal tumours. Nat Rev Urol. 2013;10(5):284-91.

19. Kutikov A, Uzzo RG. The R.E.N.A.L. nephrometry score: a comprehensive standardized system for quantitating renal tumor size, location and depth. J Urol. 2009;182(3):844-53.

20. Ficarra V, Novara G, Secco S, et al. Preoperative aspects and dimensions used for an anatomical (PADUA) classification of renal tumours in patients who are candidates for nephron-sparing surgery. Eur Urol. 2009;56(5):786-93.

21. Simmons MN, Ching CB, Samplaski MK, et al. Kidney tumor location measurement using the $C$ index method. J Urol. 2010;183(5):1708-13.

22. Leslie S, Gill IS, de Castro Abreu AL, et al. Renal tumor contact surface area: a novel parameter for predicting complexity and outcomes of partial nephrectomy. Eur Urol. 2014;66(5):884-93.

23. Eble JN, Sauter G, Epstein Jl, Sesterhenn IA. Pathology and genetics of tumours of the urinary system and male genital organs. Lyon: IARC Press; 2004.

24. Levey AS, Stevens LA, Schmid CH, et al. A new equation to estimate glomerular filtration rate. Ann Intern Med. 2009;150(9):604-12.

25. Uzzo RG1, Novick AC. Nephron sparing surgery for renal tumors: indications, techniques and outcomes. J Urol. 2001;166(1):6-18.

26. Mukkamala A, He C, Weizer AZ, et al. Long-term oncologic outcomes of minimally invasive partial nephrectomy for renal-cell carcinoma. J Endourol. 2014;28(6):649-54

27. Hou W, Ji Z. Achieving zero ischemia in minimally invasive partial nephrectomy surgery. Int J Surg. 2015;18:48-54.

28. Klatte T, Ficarra V, Gratzke C, et al. A literature review of renal surgical anatomy and surgical strategies for partial nephrectomy. Eur Urol. 2015; 68(6):980-92.

29. Porpiglia F, Bertolo R, Amparore D, et al. Mini-retroperitoneoscopic clampless partial nephrectomy for "low-complexity" renal tumours (PADUA score $\leq 8$ ). Eur Urol. 2014;66(4):778-83.

30. Rizkala ER, Khalifeh A, Autorino R, et al. Zero ischemia robotic partial nephrectomy: sequential preplaced suture renorrhaphy technique. Urology. 2013;82(1):100-4.

\section{Submit your next manuscript to BioMed Central and we will help you at every step:}

- We accept pre-submission inquiries

- Our selector tool helps you to find the most relevant journal

- We provide round the clock customer support

- Convenient online submission

- Thorough peer review

- Inclusion in PubMed and all major indexing services

- Maximum visibility for your research

Submit your manuscript at www biomedcentral.com/submit
C) BioMed Central 